Марет ПАНК, О. КИРРЕТ, Надежда ПАБЕРНТ, А. ААВНКСААР

\title{
СПЕЦИФИЧНОСТЬ НЕЙТРАЛЬНОЙ ПРОТЕАЗЫ BACILLUS BREVIS В РЕАКЦИИ С ДИПЕПТИДНЫМИ СУБСТРАТАМИ
}

Изучена субстратная специфичность по отношению к низкомолекулярным пептидным субстратам новой нейтральной металлопротеазы, выделенной из культуральной жидкости термофильной бактерии Bacillus brevis 7882. По своим ферментативным свойствам эта протеаза проявляет сходство с термолизином (КФ 3.4.24.4) из Bacillus thermopгоteolyticus [ $\left.{ }^{1-3}\right]$ : она преимущественно расщепляет пептидные связи, в образовании которых участвуют аминогруппы гидрофобных аминокислот Leu и Phe [4], что указывает на наличие соответствующей гидрофобной полости в ее активном центре.

Для количественной оценки роли этой гидрофобной полости в специфичности действия протеазы была использована серия N-3-(2-фурил) акрилоил-глицил-X-амидов $\left(\mathrm{Fa}-\mathrm{Gly}-X-\mathrm{NH}_{2}\right)$, где $X=\mathrm{Ala}, \mathrm{Abu}$, Val, Nva, Leu, Nle, D,L-Acp, Phe, Tyr (Abu - $\alpha$-аминомасляная кислота, Nva - норвалин, Nle - норлейцин, Аср - $\alpha$-аминокаприловая кислота).

\section{Экспериментальная часть}

Использовали трис фирмы «Reanal», перекристаллизованный из метанола; малеиновую кислоту марки «чда»; $\mathrm{NaOH}$ и $\mathrm{CaCl}_{2}$ марки «хч». Грамицидин $S$-агароза была синтезирована в нашей лаборатории M. Хага по методике [5].

Синтез субстратов описан в [6]. Гидролизуемую связь определяли, исследуя продукты ферментативного гидролиза тонкослойной хроматографией на пластинках Silufol (ЧССР) в системе н-бутанол-уксусная кислота-вода-пиридин $(15: 3: 12: 10)$.

Источником нейтральной металлопротеазы была бактерия B. brevis, выделенная из лабораторной культуры актиномицета Thermoactinomyces vulgaris штамм 42, который ранее считался продуцентом этого фермента [ $\left.{ }^{4,7}\right]$.

Протеазу осаждали спиртом из культуральной жидкости (4:1) и дважды очищали аффинной хроматографией на грамицидин $S$-агарозе по модифицированной методике [5]. Препарат был гомогенным при диск-электрофорезе в полиакриламидном геле при $\mathrm{pH} 4,5$. Данные о молекулярном весе и некоторых свойствах фермента будут опубликованы отдельно $\left[{ }^{8}\right]$.

Запасные растворы фермента готовили в буферах: 0,02 M трис кислый малеат - $\mathrm{NaOH}, \mathrm{pH} 8,6$ или $0,05 \mathrm{M}$ трис- $\mathrm{HCl}$, pH 8,8, содержащих 5 м $\mathrm{CaCl}_{2}$, и хранили при $4^{\circ} \mathrm{C}$. В этих условиях активность фермента сохранялась без изменения 
Кинетику гидролиза субстратов измеряли на спектрофотометре «Varian Techtron 635» (Австралия) по уменьшению оптической плотности реакционной смеси при 322 или 345 нм, используя в расчетах $\varepsilon_{322}=13400, \Delta \varepsilon_{322}=2300$ и $\Delta \varepsilon_{345}=317$ [] для всех субстратов, кроме $\mathrm{FA}-\mathrm{Gly}-\mathrm{Tyr}-\mathrm{NH}_{2}$, для которого было найдено $\varepsilon_{322}=15800$, $\Delta \varepsilon_{322}=4700$.

Константы скорости псевдопервого порядка определяли из зависимостей начальных скоростей ферментативного гидролиза субстратов от их концентраций в диапазоне $0,03-0,11$ мМ и для некоторых субстратов до концентрации 2 мМ. Наблюдавшиеся во всех случаях прямолинейные зависимости свидетельствовали о значениях $K_{m}>2$ мM. Некоторые из полученных прямых показаны на рис. 1. Измерения при более высоких концентрациях были невозможны из-за слишком большой оптической плотности растворов субстратов, поэтому определить константы $k_{\text {cat }}$ и $K_{m}$ в отдельности не удалось. В соответствии с принятой для нейтральных металлопротеаз схемой реакции

$$
E+S \stackrel{K_{m}}{\rightleftarrows} E S \stackrel{k_{\text {eat }}}{\longrightarrow} E+P_{1}+P_{2},
$$

бимолекулярные константы скорости гидролиза, $k_{\mathrm{II}}=k_{\text {cat }} / K_{m}$, вычисляли из констант псевдопервого порядка. Необходимую для этого молярную концентрацию фермента определяли по скорости гидролиза специфического субстрата FA-Gly-Leu- $\mathrm{NH}_{2}$, считая, что удельная активность чистого фермента равняется 1,05 ME в 0,05 M буфере трис- $\mathrm{HCl}, \mathrm{pH} 7,2$ при $25^{\circ} \mathrm{C}$ и концентрации субстрата 0,1 мM, а его молекулярный вес составляет 35000.

Для ряда субстратов были получены также полные кривые гидролиза первого порядка и по ним вычислены константы скоростей реакций методом Рудакова [ $\left.{ }^{10}\right]$. Кинетика реакций соответствовала псевдопервому порядку до глубины превращения субстрата $90 \%$. Найденные двумя методами константы скорости в пределах экспериментальных погрешностей совпали. Проверяли также пропорциональность начальной скорости ферментативного гидролиза концентрации фермента.

Значения констант гидрофобности $\pi_{\mathrm{R}}$ для боковых радикалов аминокислот были вычислены из алифатических значений $\pi$, причем для ароматических аминокислот $\pi_{\mathrm{R}}$ рассчитаны из $\lg P$ для бензилового и $n$-гидроксибензилового спиртов с использованием для $\mathrm{OH} \pi=$ $=-1,16[11,12]$.

\section{Результаты и их обсуждение}

Бимолекулярные константы скорости гидролиза N-3-(2-фурил)акрилоил-глицил-X-амидов под действием протеазы B. brevis приведены в табл. 1. Как видно, скорость гидролиза этих субстратов сильно зависит от природы аминокислоты $X$ и при переходе от $\mathrm{Fa}-\mathrm{Gly}-\mathrm{Ala}-\mathrm{NH}_{2}$ к $\mathrm{FA}-\mathrm{Gly}-\mathrm{Phe}-\mathrm{NH}_{2}$ возрастает на три порядка. При этом пептид 10 , содержащий D-Phe, не гидролизуется.

На рис. 2 показана зависимость $\lg k_{\mathrm{II}}$ от ппараметра $\pi_{\mathrm{R}}$, характеризующего гидрофобность бокового радикала в остатке $X$ субстратов $\mathrm{FA}-\mathrm{Gly}-\mathrm{X}-\mathrm{NH}_{2}$. Для субстратов $1-5$ и 8 эта зависимость описывается уравнением прямой

$$
\lg k_{\mathrm{II}}=(1,75 \pm 0,07) \pi_{\mathrm{R}}+(0,4 \pm 0,1)
$$

с $r=0,997$ и $s=0,0995$. Из этого можно сделать вывод, что боковая цепь остатка $X$ связывается в активном центре протеазы в специальной гидрофобной полости, аналогичной гидрофоб̆ному карману в актив- 


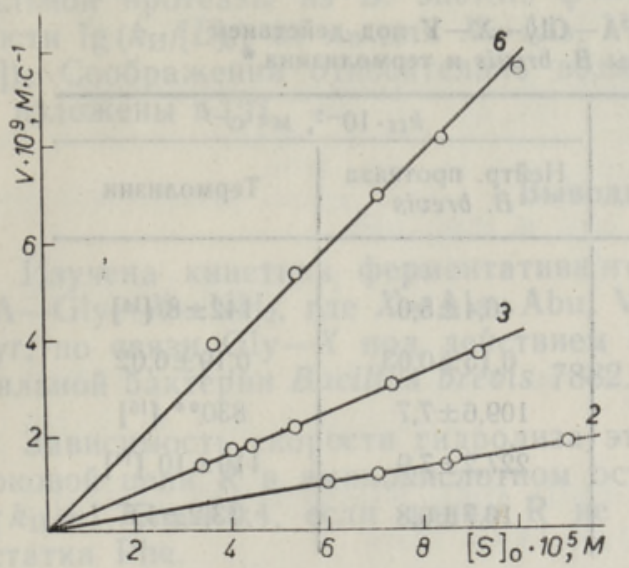

Рис. 1. Зависимость начальной скорости гидролиза амидов $\mathrm{N}$-фурилакрилоилглицил-аминокислот под действием нейтральной протеазы $B$. brevis от концентрации субстратов. Условия опытов и нумерация субстратов даны в табл. 1 (здесь и на рис. 2).

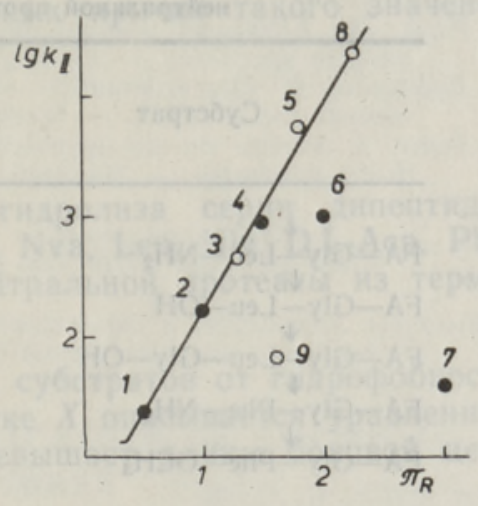

Рнс. 2. Зависимость $\lg k_{\mathrm{II}}$ от $\pi_{\mathrm{R}}$ для гидролиза нейтральной протеазой $B$. brevis амидов

$\mathrm{N}$-фурилакрилоил-глициламинокислот. Темными кружками отмечены субстраты с нормальными алифатическими радикалами в боковой цепи $X$.

Таблица 1

Гидролиз амидов N-фурилакрилоил-глицил-аминокислот

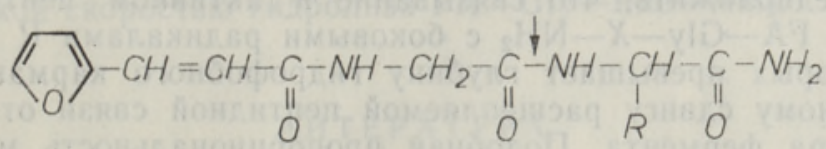

нейтральной протеазой B. brevis (стрелкой указана гидролизуемая связь)*

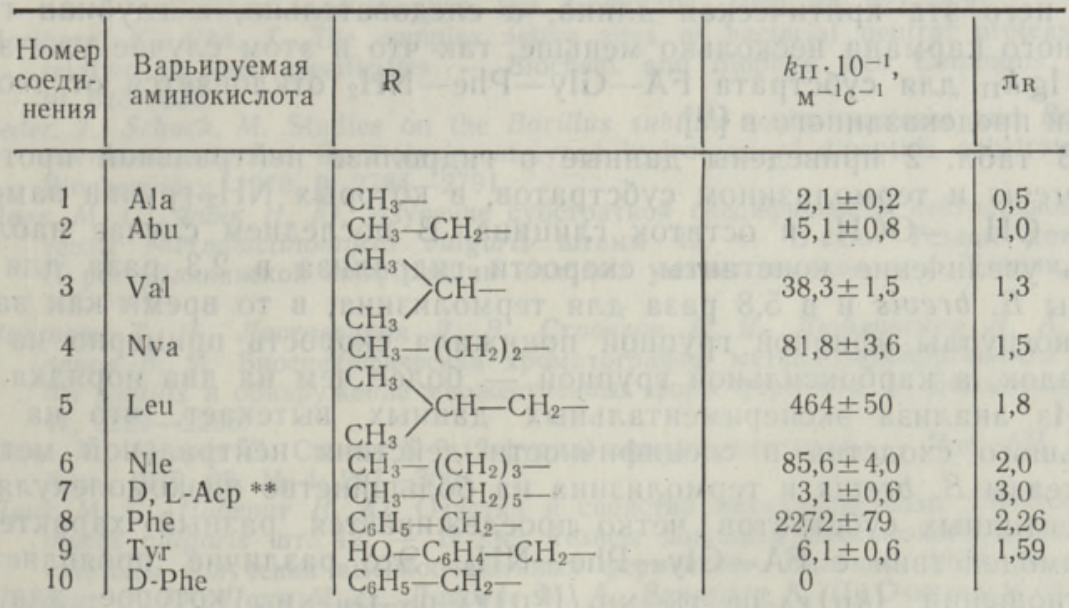

* Условия реакции: $0,17 \mathrm{M}$ трис-кислый малеат- $\mathrm{NaOH}, \mathrm{pH} 7,2$, $5 \mathrm{mM} \mathrm{CaCl}, 25^{\circ} \mathrm{C} ;[S]_{0}=0,03-0,11 \mathrm{mM},[E]=2-88 \cdot 10^{-8} \mathrm{M}$.

** Эффективную концентрацию рацемического субстрата считали равной 0,5 его общей концентрации. Возможное конкурентное ингибирование D-изомером не должно проявляться в скорости гидролиза в условиях реакции псевдопервого порядка, когда $[S]_{0} \ll K_{m}$. Это было экспериментально проверено для субстрата 8: добавление в реакционную смесь эквимолярной концентрации D-изомера не вл!ияло на скорость реакции. 
Гидролиз субстратов FA-Gly-X-Y под действием нейтральной протеазы $B$. brevis и термолизина *

\begin{tabular}{|c|c|c|}
\hline \multirow[b]{2}{*}{ Субстрат } & \multicolumn{2}{|c|}{$k_{\mathrm{II}} \cdot 10^{-2}, \mathrm{M}^{-1} \mathrm{c}^{-1}$} \\
\hline & $\begin{array}{c}\text { Нейтр. протеаза } \\
\text { B. brevis }\end{array}$ & Термолизин \\
\hline $\mathrm{FA}-\mathrm{Gly} \stackrel{\downarrow}{-}$ Leu- $-\mathrm{NH}_{2}$ & $46,4 \pm 5,0$ & $142 \pm 8\left[{ }^{14}\right]$ \\
\hline $\mathrm{FA}-\mathrm{Gly}-\mathrm{Leu}-\mathrm{OH}$ & $0,15 \pm 0,03$ & $0,19 \pm 0,02$ \\
\hline $\mathrm{FA}-\mathrm{Gly}-{ }^{\downarrow} \mathrm{Leu}-\mathrm{Gly}-\mathrm{OH}$ & $109,6 \pm 7,7$ & $830^{* *}\left[{ }^{15}\right]$ \\
\hline $\mathrm{FA}-\mathrm{Gly} \underset{\downarrow}{\downarrow} \mathrm{Phe}-\mathrm{NH}_{2}$ & $227,2 \pm 7,9$ & $110 \pm 10\left[{ }^{14}\right]$ \\
\hline $\mathrm{FA}-\mathrm{Gly}-\mathrm{\downarrow}$ he $-\mathrm{OCH}_{3}$ & $10,7 \pm 0,8$ & $13,2 \pm 1,6$ \\
\hline
\end{tabular}

* Условия опытов см. в табл. 1.

** Условия реакции: $0,05 \mathrm{M}$ трис- $\mathrm{HCl}, \mathrm{pH} 7,5,0,01 \quad \mathrm{M} \mathrm{CaCl}_{2}, 0,1 \mathrm{M}$ $\mathrm{NaCl}$.

ном центре термолизина $\left[{ }^{13,14}\right]$. Глубина полости соответствует, по-видимому, длине бензилового радикала в боковой цепи Phe, поскольку значения $\lg k_{\text {II }}$ для субстратов с более длинными боковыми радикалами (Nle, Acp, Tyr) отклоняются от корреляционной прямой. Для названных субстратов соблюдается хорошая линейная корреляция между величиной этих отклонений, $\Delta \lg k_{\text {II }}$ и $\Delta l-$ разностью между длиной бокового радикала $\mathrm{R}$ и длиной бензилового радикала. Можно предположить, что связывание в активном центре протеазы субстратов $\mathrm{FA}-\mathrm{Gly}-X-\mathrm{NH}_{2}$ с боковыми радикалами $\mathrm{R}$ в остатке $X$, длина которых превышает глубину гидрофобного кармана, приводит к невыгодному сдвигу расщепляемой пептидной связи от каталитического центра фермента. Подобная пропорциональность между $\Delta \lg k_{\mathrm{II}}$ и $\Delta l$ наблюдается также в случае термолизина, с тем различием, что для него эта критическая длина, а следовательно, и глубина гидрофобного кармана несколько меньше, так что в этом случае уже значение $\lg k_{\mathrm{II}}$ для субстрата $\mathrm{FA}-\mathrm{Gly}-\mathrm{Phe}-\mathrm{NH}_{2}$ отклоняется от теоретически предсказанного в $\left[{ }^{14}\right]$.

В табл. 2 приведены данные о гидролизе нейтральной протеазой B. brevis и термолизином субстратов, в которых $\mathrm{NH}_{2}$-группа заменена на $-\mathrm{OH},-\mathrm{OCH}_{3}$ и остаток глицина. В последнем случае наблюдалось увеличение константы скорости гидролиза в 2,3 раза для протеазы B. brevis и в 5,8 раза для термолизина, в то время как замена аминогруппы эфирной группой понижала скорость примерно на один порядок, а карбоксильной группой - более чем на два порядка.

Из анализа экопериментальных данных вытекает, что на фоне большого сходства в специфичности действия нейтральной металлопротеазы $B$. brevis и термолизина на большинство низкомолекулярных дипептидных субстратов четко прослеживается разный характер их взаимодействия c FA-Gly-Phe- $\mathrm{NH}_{2}$. Это различие проявляется в

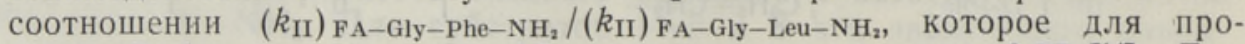
теазы B. brevis составляет 4,9, а для термолизина - 0,77 [14]. Для третьего фермента данного типа, нейтральной протеазы B. subtilis, это соотношение равно $0,045\left[{ }^{3}\right]$.

С другой стороны, соблюдение линейной зависимости $\lg k_{\mathrm{II}}$ от $\pi_{\mathrm{K}}$ по уравнению (2), которое можно написать в виде $\lg k_{\mathrm{II}}=C+\varphi^{\prime} \pi$, с наклоном $\varphi^{\prime}$ около 2 , по-видимому, является общим для бактериальных металлоэндопептидаз: для термолизина $\varphi^{\prime}=1,9 \pm 0,3\left[{ }^{14}\right]$, для нейт- 
ральной протеазы из B. subtilis $\varphi^{\prime}=1,6$ (наклон получен из зависимости $\lg \left(k_{\mathrm{II}} /[E]_{0}\right)$ от $\pi_{\mathrm{R}}$ для $X=\mathrm{Ala}, \mathrm{Val}$, Leu в серии $\mathrm{Z}-\mathrm{Gly}-X-\mathrm{NH}_{2}$ $\left.\left[{ }^{16}\right]\right)$. Соображения относительно возможных причин такого значения $\varphi^{\prime}$ изложены в $\left[{ }^{14}\right]$.

\section{Выводы}

1. Изучена кинетика ферментативного гидролиза серии дипептидов FA-Gly-X-NH , где $X=\mathrm{Ala}$, Abu, Val, Nva, Leu, Nle, D,L-Acp, Phe, $\mathrm{Tyr}$, по связи Gly-X под действием нейтральной протеазы из термофильной бактерии Bacillus brevis 7882.

2. Зависимость скорости гидролиза этих субстратов от гидрофобности боковой цепи $\mathrm{R}$ в аминокислотном остатке $X$ описывается уравнением $\lg k_{\mathrm{II}}=1,75 \pi_{\mathrm{R}}+0,4$, если длина $\mathrm{R}$ не превышает длины боковой цепи остатка Phe.

3. Радикал $\mathrm{R}$ связывается в активном центре фермента в гидрофобном кармане, глубина которого соответствует длине бензилового радикала.

4. Замена $\mathrm{NH}_{2}$-группы субстрата остатком глицина приводит к увеличению скорости ферментативного гидролиза, a- $-\mathrm{OCH}_{3}$ или $-\mathrm{OH}$ группой - к еe значительному снижению. FA-Gly-D-Phe- $\mathrm{NH}_{2}$ не гидролизуется протеазой.

5. Специфичность нейтральной протеазы Bacillus brevis 7882 в реакциях с низкомолекулярными субстратами сходна со специфичностью термолизина и нейтральной протеазы Bacillus subtilis, но отличается от них высокой скоростью гидролиза FA-Gly- $\mathrm{Phe}-\mathrm{NH}_{2}$.

\section{Л И Т Е Р А Т Р А}

1. Matsubara, $H$. Observations on the specificity of thermolysin with synthetic peptides. - Biochem. and Biophys. Res. Communs., 1966, 24, 427-430.

2. Morihara, K., Oka, T. The complex active sites of bacterial neutral proteases in relation to their specificities. - Biochem. and Biophys. Res. Communs., 1968, $30,625-630$.

3. Feder, J., Schuck, M. Studies on the Bacillus subtilis neutral-protease and Bacillus thermoproteolyticus thermolysin-catalyzed hydrolysis of dipeptide substrates. Biochemistry, 1970, 9, 2784-2791.

4. Панк М. С., Финк Н. Ю. Изучение субстратной специфичности нейтральной протеазы Thermoactinomyces vulgaris штамм 42. - В кн.: Тезисы докладов II республиканской конференции молодых ученых-химиков, ч. I. Таллин, 1977, 116-117.

5. Ваганова Т. И., Ластовецкая Л. В., Стронгин А. Я., Люблинская Л. А., Степанов B. M. Биоспецифическая хроматография металлоэндопротеиназы Bacillus subtilis и обнаружение множественных форм фермента. - Биохимия, 1976, $41,2229-2236$.

6. Панк М., Киррет О. Синтез N-3-(2-фурил)-акрилоилпептидов. - Изв. АН ЭССР. Хим., 1979, 28, № 4, 297-300.

7. Панк М. С., Паберит Н. Ю. Очнстка и свойства металлопротеазы Thermoactinomyces vulgaris шт. 42. - В кн.: Тезисы докладов Всесоюзного симпознума «Методы получения высокоочнщенных ферментов». Вильнюс, 1978, 90-91.

8. Паберит Н. Ю., Панк М. С., Лийдерс М. А., Ванаталу К. П. Очнстка и свойства нейтральной металлопротеазы Bacillus brevis 7882 (в печати).

9. Khan, S. K., Darnall, D. W. The hydrolysis of 3-(2-furyl-acryloyl)-glycyl-Lleucine amide by thermolysin. - Anal. Biochem., 1978, 86, 332-336.

10. Рудаков E. C. Дифференциальные методы расчета констант скоростей неосложненных химических реакций. - Қинетика и катализ, 1960, 1, вып. 2, 177-187.

11. Fujita, T., Iwasa, J., Hansch, C. A new substituent constant, $\pi$, derived from partition coefficients. - J. Amer. Chem. Soc., 1964, 86, 5175-5180.

12. Leo, A., Hansch, C., Elkins, D. Partition coefficients and their uses. - Chem. Rev., 1971, 71, 525-616. 
13. Colman, P. M., Jansonius, J. N., Matthews, B. W. The structure of thermolysin: an electron density map at $2,3 \AA$ resolution. - J. Mol. Biol., 1972, 70, $701-724$

14. Pank, M., Kirret, O., Paberit, N., Aaviksaar, A. Hydrophobic interaction in thermolysin specificity. - FEBS Letters, 1982, 142, 297-300.

15. Holmquist, B. Characterization of the microprotease from Bacillus cereus. A zinc neutral endoprotease. - Biochemistry, 1977, 16, 4591-4594.

16. Feder, J. Studies on the specificity of Bacillus subtilis neutral protease with synthetic substrates. - Biochemistry, 1967, 6, 2088-2093.
Ннститут химии
Академии наук Эстонской ССР
Поступила в редакцию
9/XII 1982

Ннститут химической и биологической физики

Академии наук Эстонской ССР

Maret PANK, O. KIRRET,

Nadežda PABERIT, A. AAVIKSAAR

\section{BACILLUS BREVIS'E NEUTRAALSE PROTEAASI SPETSIIFILISUS REAKTSIOONIS DIPEPTIIDSETE SUBSTRAATIDEGA}

On uuritud $\mathrm{Gly}-X$ sideme hüdrolüüsi kineetikat dipeptiidsete substraatide seerias $\mathrm{N}-3$ (2-furüül) -akrüloüül-glütsüül- $X$-amiidid (FA-Gly- $X-\mathrm{NH}_{2}$, kus $X=\mathrm{Ala}$, Abu, Val, Nva, Leu, Nle, D,L-Acp, Phe, Tyr) uue termofiilse bakteri B. brevis 7882 poolt toodetud neutraalse proteaasi abil.

Hüdrolüüsi kiirus sõltub aminohappe $X$ kõrvalahela $\mathrm{R}$ hüdrofoobsusest, kui $\mathrm{R}$ pikkus ei ületa fenüülalaniini kōrvalahela pikkust: $\lg k_{I I}=1,75 \pi_{\mathrm{R}}+0,4 \quad\left(\pi_{\mathrm{R}}\right.$ on Hanschi hüdrofoobsuskonstant). See räägib hüdrofoobse tasku olemasolust proteaasi aktiivses tsentris, kusjuures tasku sügavus näib vastavat bensüülgrupi pikkusele. Hüdrolüüsi kiirus suureneb, kui asendada substraadis lōpp-amiidgrupp glütsiiniga, ja väheneb tunduvalt, kui rühm $-\mathrm{NH}_{2}$ asendada $-\mathrm{OH}$ või $-\mathrm{OCH}_{3}$-ga, $\mathrm{FA}-\mathrm{Gly}-\mathrm{D}$-Phe- $-\mathrm{NH}_{2}$ ei hüdrolüüsu üldse.

$B$. brevis'e neutraalse proteaasi spetsiifilisus madalmolekulaarsete substraatide suhtes on üldiselt sarnane termolüsiini ja $B$. substilis'e neutraalse proteaasi spetsiifilisusega, kuid erineb märgatavalt suurema $\mathrm{FA}-\mathrm{Gly}-\mathrm{Phe}-\mathrm{NH}_{2}$ hüdrolüüsi kiiruse poolest.

Maret PANK, O. KIRRET,

Nadezhda PABERIT, A. AAVIKSAAR

\section{SPECIFICITY OF BACILLUS BREVIS NEUTRAL PROTEASE IN THE REACTION WITH DIPEPTIDE SUBSTRATES}

The kinetics of the hydrolysis of the Gly- $X$ peptide bond in a series of dipeptide substrates, N-3-(2-furyl)-acryloyl-glycyl- $X$-amides (FA-Gly- $X-\mathrm{NH}_{2}$, with $X=\mathrm{Ala}$, Abu, Val, Nva, Leu, Nle, D, L-Acp, Phe, Tyr) by a new neutral protease from thermophilic bacteria Bacillus brevis 7882 has been studied. The rate of the hydrolysis is controlled by the hydrophobicity of the side-chain $\mathrm{R}$ in $X, \lg k_{11}=1.75 \pi_{\mathrm{R}}+0.4\left(\pi_{\mathrm{R}}\right.$ is the Hansch hydrophobicity constant for R), if the length of $\mathrm{R}$ is not longer than the length of the phenylalanine side-chain. The results provide evidence for the binding of $R$ in a hydrophobic pocket in the active site of the protease. The depth of the pocket seems to correspond to the length of the benzyl group. The rate of the hydrolysis has been enhanced by the presence of the glycyl residue instead of the amide group in the substrate, and it diminished greatly if $-\mathrm{NH}_{2}$ was changed for $-\mathrm{OH}$ or $-\mathrm{OCH}_{3}$. The hydrolysis of FA- Gly-D-Phe- $-\mathrm{HN}_{2}$ was not catalyzed by the protease.

In general, the specificity of the $B$. brevis neutral protease against low-molecular peptide substrates is similar to that of thermolysin (EC 3.4.24.4) and a neutral protease from Bacillus subtilis but differs in the markedly higher speed of the hydrolysis of FA-Gly-Phe- $\mathrm{NH}_{2}$ by the $B$. brevis protease. 